\title{
Article
}

\section{Asphalt Pavement Acoustic Performance Model}

\author{
Rita Kleizienè ${ }^{1, *}$, Ovidijus Šernas ${ }^{1}$, Audrius Vaitkus ${ }^{1}$ and Rūta Simanavičienè ${ }^{2}$ \\ 1 Road Research Institute, Vilnius Gediminas Technical University, Linkmenu str. 28, \\ LT-08217 Vilnius, Lithuania; ovidijus.sernas@vgtu.lt (O.Š.); audrius.vaitkus@vgtu.lt (A.V.) \\ 2 Department of Mathematical Statistics, Vilnius Gediminas Technical University, Saulètekio av. 11, \\ LT-10223 Vilnius, Lithuania; ruta.simanaviciene@vgtu.lt \\ * Correspondence: rita.kleiziene@vgtu.lt; Tel.: +370-650-27736
}

Received: 2 April 2019; Accepted: 19 May 2019; Published: 23 May 2019

\begin{abstract}
Low-noise pavements are used as an effective method of traffic noise mitigation. Low-noise pavements reduce the noise that arises due to interactions between tires and road surfaces (tire/road) via the implementation of three main components: low pavement roughness, negative pavement texture, and a high pavement air-void content. The tire/road noise reduction capabilities of the wearing layer vary depending on the aggregate type, gradation, bitumen and air-void content, and density. Consequently, the demand for an accurate tire/road noise prediction model has arisen from the design of asphalt mixtures. This paper deals with how asphalt mixture components of the wearing layer influence tire/pavement noise reduction and presents a model for tire/road noise level prediction based on the asphalt mixture composition. The paper demonstrates that the noise reduction level of low-noise asphalt pavements is dependent on the composition of the asphalt mixture. Asphalt wearing layer mixture composition parameters were tested in the laboratory from cores taken from 18 road sections, where acoustic properties were measured using a close-proximity (CPX) method. The proposed linear model is based on the bitumen amount, the air-void content of the mixture and aggregate shape and involves materials that comply with the general requirements for high-quality asphalt mixtures. The model allows for the prediction of the tire/road noise level at the asphalt mixture design stage using asphalt mixture components and volumetric properties. The proposed model is the first stage in the building of a complex model with a much wider range of low-noise asphalts components, pavement profile depth and CPX-value relationships.
\end{abstract}

Keywords: tire/road noise; close-proximity method; CPX; low-noise asphalt; low-noise pavement; acoustic properties; noise prediction; prediction model

\section{Introduction}

Over the past several decades, society and authorities' demands for an unpolluted, health-friendly, and reduced traffic noise environment have increased dramatically. According to the World Health Organization, every year traffic noise induces cardiovascular disease in at least 1 million Europeans [1]. Annual social economic expenses of traffic noise exceed 40 billion EUR, of which $90 \%$ were caused by road-transport-generated noise [2]. Road transport noise is caused by noise from propulsion, aerodynamic resistance, and noise from tire and pavement interactions [3-5]. However, tire/road noise due to tire and pavement interactions is dominant at speeds above $40 \mathrm{~km} / \mathrm{h} \mathrm{[6]} \mathrm{and} \mathrm{is} \mathrm{influenced} \mathrm{by} \mathrm{four}$ major factors [7-10]: pavement surface characteristics (surface texture, friction, aggregate properties, air-void content (porosity), pavement materials and their properties, pavement age, and durability); tire characteristics (tire dimensions, rubber hardness, trend pattern, tire age and wear, studs, and tire number); environmental factors (temperature, moisture, wind, water film thickness, and dust); and driver-controlled factors (driving speed, tire load and pressure, tangential forces, and acceleration). 
Bezemer-Krijnen et al. [11] investigated several tire-trend parameters and road characteristics that influence tire/road noise generation and determined that sound abortion and porosity have more effect at higher frequencies. The researchers also stated that tires with a large continuity pattern generate less sound.

Since environmental factors and tire characteristics, as well as driver-controlled factors, are difficult to control; pavement surface characteristic optimization for reducing tire/road noise is a major task for road engineers and researchers. The tire/road noise can be primarily interpreted by defining the noise level determined at a speed of $96.6 \mathrm{~km} / \mathrm{h}(60 \mathrm{mph})$ by performing noise measurements with on-board sound intensity (OBSI), close-proximity (CPX), or a similar method [12]: low noise level—up to 99-100 dBA; medium noise level—from 99-100 dBA to 104-105 dBA; and high noise level—more than 104-105 dBA.

The purpose of this study was to investigate asphalt mixtures and pavements, which can be defined as having a low noise level and to develop a model for tire/road noise estimation from asphalt mixture compositions. The research scope of the work involved:

- Identifing field test sections with a low noise of road surfaces for field noise evaluation and asphalt mixture composition evaluation.

- Collecting field core samples of the various pavement types.

- Assembling and documenting the mixture's material properties and field noise measurements.

- Analyzing correlations between the asphalt mixture's composition and volumetric properties and noise level.

- Observing the asphalt pavement's acoustical performance (noise) prediction models using mathematical relationships, which are fundamentally based on the road mixture's volumetric properties.

- $\quad$ Evaluating the sensitivity of the established noise-level prediction model.

\section{Background of Pavement Acoustical Performance}

Newly-constructed low-noise asphalt pavements usually produce a 3-9 dBA lower noise compared to the reference; however, the noise reduction decreased rapidly with time [13]. The tire/road noise level and its change during usage of pavement depends on the surface roughness [14]. Also, the acoustical aging is related to changes in the pavement surface texture [15]. Therefore, the biggest challenge was to develop an asphalt mixture/layer with increased resistance to wearing and permanent deformation.

The stone mastic asphalt (SMA) and porous asphalt (PA) are the most popular asphalt mixtures for use as the pavement wearing layer to reduce the tire/road noise in European countries. However, for cold regions, a pavement made from porous asphalt is not recommended due to the clogging of the pores. Son et al. [14] analyzed the SMA mixture design according to the Bailey method and determined that a surface layer with 4.75 SMA showed a significantly lower nose level than the control mixture. Vaitkus et al. [16] stated that low-noise asphalt mixtures must be designed based on the evaluation of additional properties such as binder drain-down, resistance to ravelling, the evolution of the surface texture, and permeability.

An extended literature review of several researcher outcomes [17-22] allowed for the determination of correlations between the air-void content and noise level (see Figure 1) and mean profile depth (see Figure 2). Based on other researcher's measurements, it can be seen that a low-noise-level (below $100 \mathrm{~dB}$ ) asphalt mixture can contain 2.3\%-28.5\% air-voids; however, all asphalt layers with an air-void content of more than $8 \%$ assures less than $98.5 \mathrm{~dB}$ noise (see Figure 1). Literature analysis also showed a linear correlation between the mean profile depth and air-void content (see Figure 2). However, Remisova et al. [23] stated that no close relationship exists between the surface characteristics (absolute measured surface texture and mean profile depth (MPD)) and mixture air-void content. 


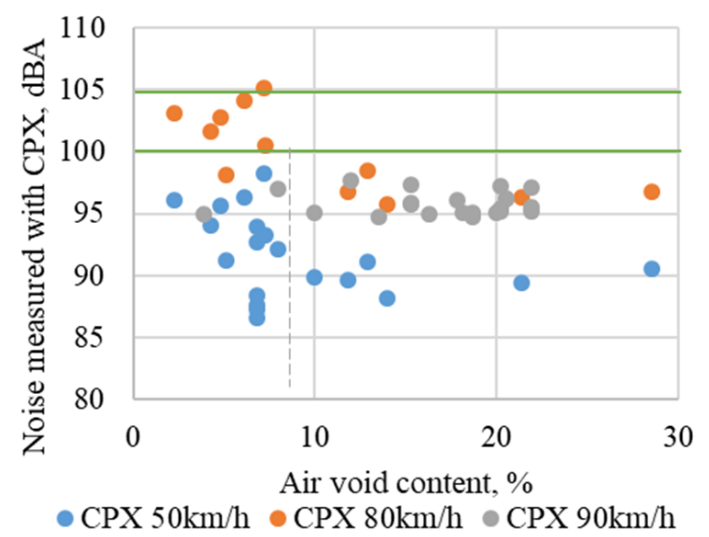

Figure 1. Noise measured with close-proximity (CPX) and air-void content of asphalt layer based on literature review [17-20].

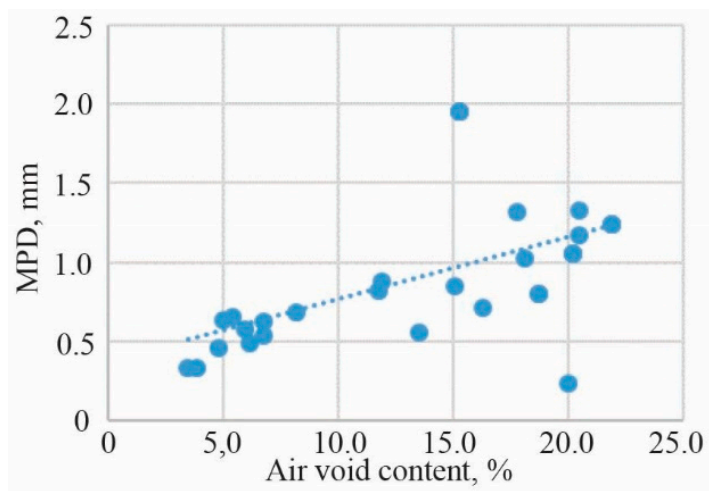

Figure 2. Mean profile depth and air-void content of asphalt layer based on literature review [17,20,21].

The influence of texture on tire/road noise at different speeds is the focus of many researchers trying to find quantitative relations [8]. The acoustical absorption of the pavement depends on porosity, texture, airflow resistance, and thickness. Commonly, noise characteristics are predicted by the estimated road noise level (ERNL), which are based on texture levels categorized into bands of octaves [24-26]. Losa et al. [25] investigated the relationship between asphalt texture level and rolling noise level at different speeds and presented a multivariate linear regression model with two independent variables at high and low frequency. Losa et al. [25] improved the ERNL model for noise prediction in dense and semi-porous asphalt surfaces based on the driving speed and texture level.

Wu et al. [27] developed an acoustic prediction model based on a curve fitting technique by applying a grey model $(\mathrm{GM}(1,2))$. The model was built on limited data that were used to predict the next output data from the sequence, the GM $(1,2)$ model. Researchers stated that the GM $(1,2)$ model is not limited to the physical and geometrical parameters of the pavement.

Chen et al. [22] developed a sound-absorption model which allows for the prediction of porous pavement noise at different speeds based on asphalt pavement surface properties and the acoustic absorption coefficient of the asphalt mixture.

Zofka et al. [4] analyzed tire/road noise measured with the OBSI method and presented prediction models based on two main factors: measurement speed and pavement surface type (Portland cement concrete, SMA and hot mix asphalt). Pratico [28] analyzed a physical model for noise estimation-based geometry, traffic speed, parameters related to the atmosphere, road surface, and wearing-layer characteristics. However, the suggested model used an overly complicated mathematical solution to estimate the noise-absorption coefficient for evaluation of the pavement properties, sound generation, geometry, and human perception. 


\section{Materials and Methods}

\subsection{Low-Noise Pavement Sections}

Pavement surfaces of experimental sections were composed of low-noise open-graded and porous asphalt wearing layers, with the exception of a section that used a traditional asphalt layer. The research was carried out for pavements constructed in 2015-2018, and measurements were conducted at the first year of exploitation. For each pavement section, the percentage of air voids and mean value of tire/road noise level was determined. A summary of the analyzed pavement sections is given in Table 1.

In the experimental research, a database was formed using data from 18 road sections with 64 testing locations: 19 samples with asphalt concrete AC $11 \mathrm{VN}, 1$ sample with asphalt concrete AC $11 \mathrm{VS}, 1$ sample with asphalt concrete AC 11 PAS-H, 1 sample with porous asphalt PA 8, 10 samples sections with soft asphalt SA 16, 11 samples with stone mastic asphalt SMA 11 S, 15 samples with stone mastic asphalt SMA $8 \mathrm{~S}, 1$ sample with stone mastic asphalt SMA 5 TM, 4 test sections with stone mastic asphalt SMA 8 TM, and 1 test section with asphalt concrete TMOA 5.

Table 1. Summary of analyzed pavement sections.

\begin{tabular}{|c|c|c|c|c|c|c|c|}
\hline \multirow{2}{*}{$\begin{array}{c}\text { ID of Pavement } \\
\text { Section }\end{array}$} & \multirow{2}{*}{ Road No. } & \multirow{2}{*}{$\begin{array}{c}\text { No of } \\
\text { Samples }\end{array}$} & \multirow{2}{*}{$\begin{array}{c}\text { Mixture } \\
\text { Type Code }\end{array}$} & \multicolumn{2}{|c|}{ Section, km } & \multirow{2}{*}{$\begin{array}{c}\text { Traffic } \\
\text { AADT, v./d. }\end{array}$} & \multirow{2}{*}{$\begin{array}{l}\text { Category of } \\
\text { Road }\end{array}$} \\
\hline & & & & From & To & & \\
\hline 1. & $\mathrm{~A} 2$ & 1 & SMA $8 \mathrm{~S}$ & 56.07 & 56.17 & 12187 & Main road \\
\hline 2. & $\mathrm{~A} 2$ & 1 & SMA $11 \mathrm{~S}$ & 56.17 & 56.35 & 12187 & Main road \\
\hline 3. & A2 & 1 & AC $11 \mathrm{VS}$ & 56.35 & 56.52 & 12187 & Main road \\
\hline 4. & A2 & 1 & PA 8 & 56.52 & 56.70 & 12187 & Main road \\
\hline 5. & $\mathrm{~A} 2$ & 1 & TMOA 5 & 56.70 & 56.87 & 12187 & Main road \\
\hline 6. & $\mathrm{~A} 2$ & 1 & AC 8 PAS-H & 56.87 & 57.05 & 12187 & Main road \\
\hline 7. & $\mathrm{~A} 2$ & 1 & SMA 5 TM & 57.05 & 57.22 & 12187 & Main road \\
\hline 8. & $\mathrm{~A} 2$ & 1 & SMA 8 TM & 57.22 & 57.40 & 12187 & Main road \\
\hline 9. & A14 & 3 & SMA $11 \mathrm{~S}$ & 48.00 & 49.00 & 5791 & Main road \\
\hline 10. & A17 & 6 & SMA 8 S & 8.90 & 10.50 & 9816 & Bypass \\
\hline 11. & A17 & 2 & SMA 8 S & 10.53 & 22.06 & 9816 & Bypass \\
\hline 12. & 1245 & 1 & SMA 8 TM & 0.00 & 2.04 & 635 & Regional road \\
\hline 13. & 173 & 19 & AC $11 \mathrm{VN}$ & 36.00 & 37.00 & 708 & National road \\
\hline 14. & 4307 & 10 & SA 16 & 1.00 & 2.00 & 292 & Regional road \\
\hline 15. & A15 & 7 & SMA $11 \mathrm{~S}$ & 12.00 & 13.00 & 7904 & Main road \\
\hline 16. & A16 & 6 & SMA 8 S & 28.00 & 29.00 & 7327 & Main road \\
\hline 17. & $\begin{array}{l}\text { J. Tilvičio street., } \\
\text { Panevėžys city }\end{array}$ & 1 & SMA 8 TM & - & - & - & City street \\
\hline 18. & $\begin{array}{l}\text { J. Tilvičio street., } \\
\text { Panevėžys city }\end{array}$ & 1 & SMA 8 TM & - & - & - & City street \\
\hline
\end{tabular}

Where: $\mathrm{v}$./d.: vehicle per day; AADT: annual average daily traffic; SMA: stone mastic asphalt; PA: porous asphalt; AC: dense asphalt concrete (HMA).

\subsection{Tests Methods}

Volumetric composition of asphalt mixtures was tested for specimens (cores) taken from pavement sections according to standard EN 12697-27 [29]. In one location, at least three specimens were cored, and volumetric characteristics were used for the calculation of average values from all specimens. Void characteristics of asphalt mixtures were calculated according to standard EN 12697-8 [30]. The air-void content of a bituminous specimen was calculated using the maximum density of the mixture and the bulk density of the specimen. The percentage of the voids in the mineral aggregate of a bituminous specimen filler with binder was calculated from the binder content, the voids in the mineral aggregate, the bulk density of the specimen, and the density of the binder.

The specific surface area of the aggregate was determined from a sieve analysis based on the total percentage of aggregates that passes through a stipulated group of sieves according to [31]:

$$
S A=\frac{1}{100} \times \sum_{i=0}^{N}\left(P P_{i} \times C P_{i}\right)=\frac{1}{100} \times \sum_{i=0}^{N}\left(P R_{i} \times C R_{i}\right)
$$


where $S A$-specific surface area of the aggregate $\left(\mathrm{m}^{2} / \mathrm{kg}\right) ; P P_{i}$ - percent of aggregate by weigh passing the $i$ th sieve; $C P_{i}$ - surface area factor $\left(\mathrm{m}^{2} / \mathrm{kg}\right) ; P R_{i}$ - percent of aggregate by weight retained in the $i$ th sieve; $C R_{i}$-specific surface of the particles with diameter in the range $\left(D_{i}, C_{i-1}\right),\left(\mathrm{m}^{2} / \mathrm{kg}\right) ; i$-sieve index $(i=0,1, \ldots, N)$; and $N$ - set of sieves for the analysis.

The close-proximity method was used for noise level measurements. The noise measurements were performed using an approved CPX device (Figure 3) which participates in annual field calibrations. The acoustic performance of the pavement was measured as a noise generated by the test tire by means of two or more microphones located close to the contact surface on a vehicle driven at different speeds. The tire/road noise level was determined as the arithmetic mean of microphone pressure levels at a certain speed. The noise-level measurements were tested at a reference speed of $80 \mathrm{~km} / \mathrm{h}$, according to ISO/CD 11819-2 [32] requirements.

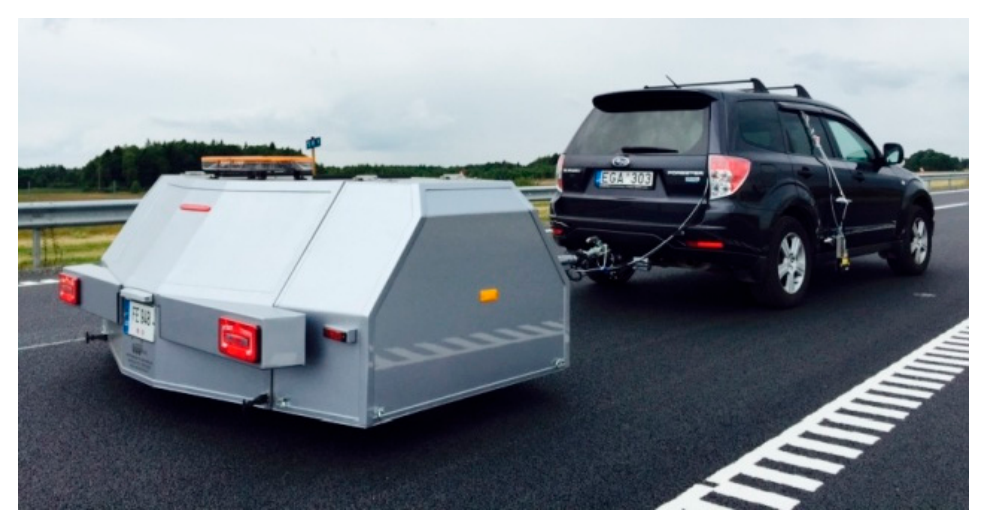

Figure 3. CPX device during noise measurement of pavement sections.

\subsection{Analysis Methods}

The research data consist of quantitative interval variables; therefore, a linear multi-regression model was chosen:

$$
Y_{i}=\beta_{0}+\beta_{1} x_{1 i}+\beta_{2} x_{2 i}+\ldots+\beta_{k} x_{k i}+e_{i}
$$

where $Y_{i}$ is the $i$ th value of the dependent variable; $x_{k i}$ is the $i$ th value of $k$ th independent variable; $\hat{\mathrm{A}}_{k}$ is the unknown regression coefficient; the $e_{i}$ is the residual of observation $i$.

The model should conform to the assumptions of linear regression:

- Linear relationship. The relationships between $Y_{i}$ and each of the independent variables $X_{i}$, $(i=\overline{1, k})$ are linear. This assumption was tested by calculating the Pearson coefficient of correlation.

- No or little multicollinearity. Multicollinearity occurs when the independent variables are not independent of each other. This assumption was tested using variance inflation factor (VIF) values. A variance inflation factor quantifies how much the variance is inflated. The standard errors and the variances of the estimated coefficients are inflated when a multicollinearity exists. The variance inflation factor $\mathrm{VIF}_{i}$ for the estimated coefficient $\hat{\mathrm{A}}_{i}$ is calculated using the formula:

$$
\mathrm{VIF}_{i}=\frac{1}{1-R_{i}^{2}},
$$

where $R_{i}^{2}$ is the $R^{2}$ - the value obtained by $X_{i}$ and each of the independent variables. $\operatorname{If~}_{\operatorname{VIF}_{i}}>4$, the variable $X_{i}$ causes the problem of multicollinearity in the model [33].

- Multivariate normality. Multiple regression assumes that the residuals are normally distributed. This assumption is tested using the Shapiro-Wilk test. If the test statistic has a $p$-value $<0.05$, then the null hypothesis that residuals are normally distributed is rejected. 
- Homoscedasticity. This assumption states that the variance of error terms is similar across the values of the independent variables. This assumption was tested using the Breusch-Pagan test. Before deciding upon an estimation method, one may conduct the Breusch-Pagan test to examine the presence of heteroscedasticity. The Breusch-Pagan test assumes that the error terms are normally distributed. If the test statistic has a $p$-value $<0.05$, then the null hypothesis of homoscedasticity is rejected, and heteroscedasticity is assumed [34].

- Outliers. We assume that all special causes, outliers due to one-time situations, have been removed from the data. If not, they may cause a non-constant variance, non-normality, or other problems with the regression model. This assumption was tested using the Bonferroni test. If the test statistic has a $p$-value $<0.05$, then it is assumed that the data contain outliers [35].

The coefficient of determination, $R^{2}$, provides a measure of how well-observed outcomes are replicated by the model, based on the proportion of the total variation of outcomes explained by the model. If $R^{2} \geq 0.20$, one can assume that the model effectively describes the data.

\section{Results and Analysis}

\subsection{Properties of Low-Noise Asphalt Mixtures}

All mixtures for high traffic levels were designed using granite aggregates and polymer-modified bitumen, while asphalt mixtures for light traffic (SA16-d V6000 C and AC $11 \mathrm{VN}$ ) were designed using crushed gravel aggregates and softer bitumen (respectively V6000 and 70/100). A summary of the properties of the asphalt mixtures components is given in Table 2.

The properties of asphalt mixtures of analyzed pavement sections were determined and analyzed in Table 3. The aggregate granular composition for dominant asphalt mixtures is shown in Figure 4. From analysis of the asphalt mixture database, it can be stated that asphalt mixture gradation depends on the manufacturer-comparing the results of the same asphalt mixture type showed that, in some cases, passing values varied from $5 \%$ to $10 \%$.

Table 2. The main properties of the asphalt mixture components.

\begin{tabular}{|c|c|c|c|c|}
\hline Asphalt Mixture & $\begin{array}{c}\text { Bitumen } \\
\text { Binder Type }\end{array}$ & $\begin{array}{l}\text { Polished Stone } \\
\text { Value (PSV) }\end{array}$ & $\begin{array}{l}\text { Shape Index } \\
\text { (SI) }\end{array}$ & $\begin{array}{l}\text { Flakiness Index } \\
\text { (FI) }\end{array}$ \\
\hline $\mathrm{AC} 11 \mathrm{VN}$ & $70 / 100$ & 50 & 10 & 8 \\
\hline AC $11 \mathrm{VS}$ & PMB 45/80-55 & 53 & 5 & 5 \\
\hline AC 8 PAS-H & PMB 40/100-65 & - & - & - \\
\hline PA 8 & PMB 40/100-65 & - & - & - \\
\hline SA 16 & V6000 & 50 & 10 & 8 \\
\hline SMA $11 \mathrm{~S}$ & PMB 45/80-55 & 53 & 5 & 5 \\
\hline SMA 5 TM & PMB 40/100-65 & 53 & 5 & 5 \\
\hline SMA 8 TM & PMB 40/100-65 & 53 & 5 & 5 \\
\hline SMA 8 S & $\begin{array}{c}\text { PMB 45/80-55; PMB } \\
\text { 25/55-60 }\end{array}$ & 53 & 5 & 5 \\
\hline TMOA 5 & PMB 40/100-65 & 53 & 5 & 5 \\
\hline
\end{tabular}




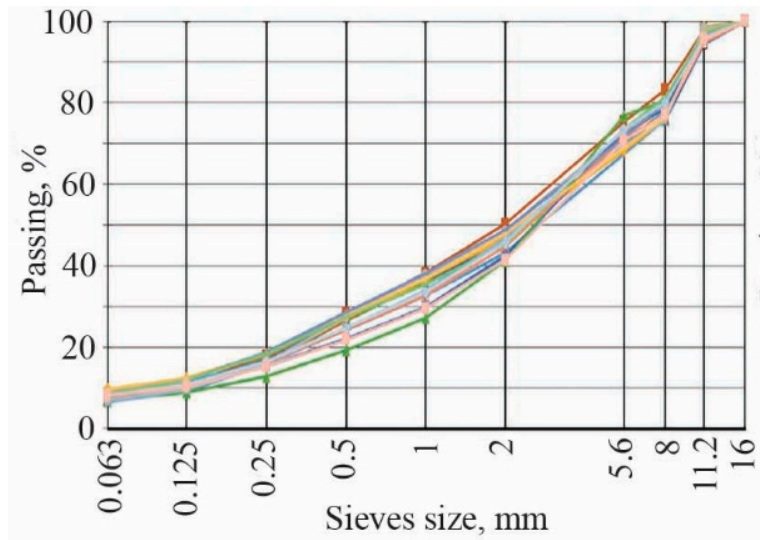

(a)

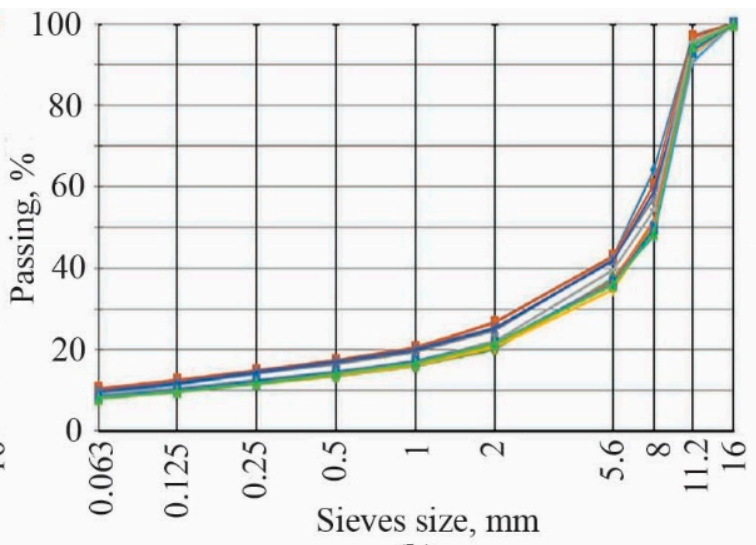

(b)

Figure 4. Aggregate gradations of dominant asphalt mixtures AC 11 VN (a) and SMA 11 S (b).

Table 3. Properties of asphalt mixtures and noise measurement results of analyzed pavement sections. VA: air-void content; SA: specific surface area of the aggregate; VMA: voids in mineral aggregate; VFB: voids filed with bitumen; Gmb: bulk specific gravity of compacted mixture.

\begin{tabular}{|c|c|c|c|c|c|c|c|c|c|c|}
\hline \multirow{2}{*}{$\begin{array}{c}\text { ID of } \\
\text { Section }\end{array}$} & \multirow{2}{*}{$\begin{array}{l}\text { ID of } \\
\text { Mixture }\end{array}$} & \multirow{2}{*}{$\begin{array}{l}\text { Mixture } \\
\text { Type } \\
\text { Code }\end{array}$} & \multirow{2}{*}{$\begin{array}{c}\text { Test } \\
\text { Location in } \\
\text { Section }\end{array}$} & \multicolumn{7}{|c|}{ Average Parameters } \\
\hline & & & & $\begin{array}{c}\text { Bitumen } \\
\text { Content, \% }\end{array}$ & $\begin{array}{l}\text { VA, } \\
\%\end{array}$ & $\begin{array}{c}\mathrm{SA}, \\
\mathrm{m}^{2} / \mathrm{kg}\end{array}$ & $\begin{array}{l}\text { VMA, } \\
\%\end{array}$ & $\begin{array}{c}\text { VFB, } \\
\%\end{array}$ & $\begin{array}{l}\mathrm{Gmb}, \\
\mathrm{kg} \mathrm{m}^{3}\end{array}$ & $\begin{array}{c}\text { CPX_80, } \\
\text { dB }\end{array}$ \\
\hline 2. & 2 & SMA $11 \mathrm{~S}$ & 1 & 5.87 & 1.94 & 6.25 & 15.75 & 87.67 & 2.423 & 98.7 \\
\hline 3. & 3 & AC $11 \mathrm{VS}$ & 1 & 5.00 & 2.87 & 6.05 & 14.71 & 80.53 & 2.441 & 98.5 \\
\hline 4. & 4 & PA 8 & 1 & 6.46 & 21.39 & 3.09 & 33.56 & 36.25 & 1.940 & 95.1 \\
\hline 7. & 7 & SMA 5 TM & 1 & 6.49 & 11.99 & 5.61 & 26.37 & 54.54 & 2.283 & 97.5 \\
\hline 8. & 8 & SMA 8 TM & 1 & 6.88 & 6.29 & 4.71 & 22.21 & 71.65 & 2.382 & 97.2 \\
\hline 9. & $9-11$ & SMA $11 \mathrm{~S}$ & 3 & 6.57 & 1.88 & 6.51 & 17.10 & 89.10 & 2.387 & 98.8 \\
\hline 10. & $12-17$ & SMA 8 S & 6 & 6.50 & 10.45 & 3.70 & 24.60 & 57.60 & 2.249 & 96.8 \\
\hline 11. & $18-19$ & SMA 8 S & 2 & 6.08 & 11.25 & 3.46 & 24.40 & 54.00 & 2.234 & 95.5 \\
\hline 12. & 20 & SMA 8 TM & 1 & 6.15 & 9.88 & 4,00 & 23.44 & 57.87 & 2.272 & 93.9 \\
\hline 17. & 63 & SMA 8 TM & 1 & 6.02 & 8.21 & 4.82 & 21.94 & 62.59 & 2.349 & 95.5 \\
\hline 18. & 64 & SMA 8 TM & 1 & 6.25 & 7.90 & 4.44 & 21.98 & 64.07 & 2.321 & 97.1 \\
\hline
\end{tabular}

\subsection{Properties of Low-Noise Asphalt Mixtures}

Seeking to identify the effect of asphalt mixture parameters on noise when driving on asphalt pavement at a speed of $80 \mathrm{~km} / \mathrm{h}$, a regression model was developed through analysis of 64 observations. The dependent variable selected for the model was the asphalt pavement noise criterion, CPX80 (dB), the values of which were measured on-site at a speed of $80 \mathrm{~km} / \mathrm{h}$.

The following data on the asphalt mixture were used for evaluation of the properties of low-noise asphalt mixture (AC): bitumen content $\mathrm{Pb}(\%)$, calculated surface area of aggregates $\mathrm{SA}\left(\mathrm{m}^{2} / \mathrm{kg}\right)$, density of the mineral aggregate $\mathrm{Gsb}\left(\mathrm{kg} / \mathrm{m}^{3}\right)$, effective specific gravity Gse, apparent density of the AC mixture $\mathrm{Gmb}\left(\mathrm{kg} / \mathrm{m}^{3}\right)$, maximum asphalt mixture density $\mathrm{Gmm}\left(\mathrm{kg} / \mathrm{m}^{3}\right)$, calculated air-void content VA (\%), total bitumen content in the AC mixture VB (\%), voids in the mineral aggregate VMA (\%) and voids in the mineral aggregate filled with bitumen VFB (\%). The independent variables for the model were selected after analyzing 19 criteria. These criteria were divided into two groups: factual gradation of asphalt mixture aggregates and data of the asphalt mixture determined in a laboratory. Factual aggregate gradation is described as the percent passing through nine different types of sieves 
no and mesh size: p0.063-0.063 mm, p $0.125-0.125 \mathrm{~mm}, \mathrm{p} 0.25-0.25 \mathrm{~mm}, \mathrm{p} 0.5-0.5 \mathrm{~mm}, \mathrm{p} 1-1.0 \mathrm{~mm}$, p2-2.0 mm, p5.6-5.6 mm, p8 $-8.0 \mathrm{~mm}$, and p11.2-11.2 $\mathrm{mm}$.

In order to determine the weight of each criterion, the entropy weighting method was applied [36]. The calculated weights of criteria for SA, VA, Pb, VMA, and VFB are given in Table 4. According to the criteria weights, the criterion with the largest weight is VA and the criterion with the least weight is $\mathrm{Pb}$. Analysis of the weights of gradation criteria using the entropy weighing method showed that the most dominant were aggregates passing through a sieve size of $2.0 \mathrm{~mm}(\mathrm{p} 2)$ and the least dominant were aggregates passing through a $11.2 \mathrm{~mm}$ sieve size (p11.2, Table 5).

Table 4. Weights of criteria voids in mineral aggregate (VMA), voids filled with bitumen (VFB), bitumen content $(\mathrm{Pb})$, surface area of aggregates (SA), and air-voids (VA).

\begin{tabular}{cccccc}
\hline Criteria & VMA & VFB & Pb & SA & VA \\
\hline Weights & 0.0702 & 0.0483 & 0.0249 & 0.1125 & 0.7440 \\
\hline
\end{tabular}

Table 5. Weights of criteria for the granular composition of asphalt mixtures.

\begin{tabular}{cccccccccc}
\hline Sieve Size no & p0.063 & p0.125 & p0.25 & p0.5 & p1 & p2 & p5.6 & p8 & p11.2 \\
\hline Weights & 0.0847 & 0.0729 & 0.0949 & 0.1563 & 0.1929 & 0.2059 & 0.1364 & 0.0503 & 0.0056 \\
\hline
\end{tabular}

The selection of the variables to be included in a regression model was based on the correlation of the independent variables with a dependent variable. The correlation of variables was determined by calculating the Pearson correlation coefficient:

$$
r=\frac{\sum_{i=1}^{n}\left(X_{i}-\bar{X}\right)\left(Y_{i}-\bar{Y}\right) / n}{\sqrt{\left(\sum_{i=1}^{n}\left(X_{i}-\bar{X}\right)^{2} / n\right)\left(\sum_{i=1}^{n}\left(Y_{i}-\bar{Y}\right)^{2} / n\right)}}
$$

where $\left(X_{i}, Y_{i}\right)$-a pair of values of the variables $X$ and $Y,(i=\overline{1, n}), n$-sample size.

A correlation matrix (Table 6) showed that noise level CPX80 is highly correlated with p8, p11.2, Gsb, Gmb, VA, VMA, and VFB). Therefore, it should be included in the model if they have no intercorrelation among them. According to Table 6, some of the selected criteria were correlated. In order to find out if these correlations are statistically significant, the hypothesis regarding the significance of correlation coefficients was tested.

Conclusions on the significance of the correlation coefficients were made by observing the $p$-values and comparing them with the selected significance level $\alpha=0.05$. Correlation of variables was statistically significant when $p<\alpha$. Analysis of the data in Table 7 showed that correlation between the following pairs of variables was not significant: SA with $\mathrm{p} 8, \mathrm{p} 11,2$ and $\mathrm{Pb}$; VA with $\mathrm{Pb}$ and Gsb, although the correlation between SA and VA $(r=-0.65)$ was statistically significant. A statistically significant correlation was observed between SA and VMA, SA and VFB, VA and VMA, VA and VFB, and also between VMA and VFB. It is not possible for the model to contain non-correlated criteria.

Table 6. Correlation matrix of the variables.

\begin{tabular}{ccccccccccc}
\hline & CPX80 & p0063 & p0125 & p025 & p05 & p1 & p2 & p56 & p8 & p112 \\
\hline CPX80 & 1.00 & 0.26 & 0.35 & 0.37 & 0.35 & 0.36 & 0.38 & 0.27 & -0.70 & -0.37 \\
p0063 & 0.26 & 1.00 & 0.96 & 0.73 & 0.51 & 0.40 & 0.34 & 0.26 & 0.06 & 0.52 \\
p0125 & 0.35 & 0.96 & 1.00 & 0.89 & 0.72 & 0.63 & 0.57 & 0.48 & 0.02 & 0.45 \\
p025 & 0.37 & 0.73 & 0.89 & 1.00 & 0.95 & 0.90 & 0.87 & 0.78 & 0.02 & 0.31 \\
p05 & 0.35 & 0.51 & 0.72 & 0.95 & 1.00 & 0.99 & 0.97 & 0.87 & -0.01 & 0.20 \\
p1 & 0.36 & 0.40 & 0.63 & 0.90 & 0.99 & 1.00 & 0.99 & 0.89 & -0.04 & 0.13 \\
p2 & 0.38 & 0.34 & 0.57 & 0.87 & 0.97 & 0.99 & 1.00 & 0.93 & -0.06 & 0.05 \\
\hline
\end{tabular}


Table 6. Cont.

\begin{tabular}{|c|c|c|c|c|c|c|c|c|c|c|}
\hline & CPX80 & p0063 & p0125 & p025 & p05 & p1 & p2 & p56 & p8 & p112 \\
\hline p56 & 0.27 & 0.26 & 0.48 & 0.78 & 0.87 & 0.89 & 0.93 & 1.00 & -0.01 & 0.00 \\
\hline p8 & -0.70 & 0.06 & 0.02 & 0.02 & -0.01 & -0.04 & -0.06 & -0.01 & 1.00 & 0.70 \\
\hline p112 & -0.37 & 0.52 & 0.45 & 0.31 & 0.20 & 0.13 & 0.05 & 0.00 & 0.70 & 1.00 \\
\hline $\mathrm{Pb}$ & -0.26 & 0.51 & 0.34 & -0.01 & -0.22 & -0.33 & -0.41 & -0.43 & 0.42 & 0.73 \\
\hline SA & 0.37 & 0.87 & 0.97 & 0.97 & 0.87 & 0.80 & 0.75 & 0.67 & 0.02 & 0.39 \\
\hline Gsb & -0.44 & 0.00 & 0.11 & 0.34 & 0.42 & 0.44 & 0.46 & 0.52 & 0.79 & 0.40 \\
\hline Gse & -0.56 & -0.18 & -0.30 & -0.46 & -0.54 & -0.58 & -0.58 & -0.41 & 0.54 & 0.40 \\
\hline $\mathrm{Gmb}$ & 0.72 & 0.33 & 0.47 & 0.58 & 0.59 & 0.60 & 0.61 & 0.52 & -0.51 & -0.29 \\
\hline $\mathrm{Gmm}$ & -0.43 & -0.54 & -0.55 & -0.45 & -0.40 & -0.36 & -0.30 & -0.09 & 0.30 & -0.09 \\
\hline VA & -0.76 & -0.47 & -0.60 & -0.65 & -0.64 & -0.64 & -0.63 & -0.47 & 0.54 & 0.21 \\
\hline VMA & -0.73 & -0.19 & -0.36 & -0.55 & -0.63 & -0.67 & -0.69 & -0.56 & 0.62 & 0.46 \\
\hline \multirow[t]{2}{*}{ VFB } & 0.69 & 0.63 & 0.72 & 0.72 & 0.68 & 0.65 & 0.61 & 0.45 & -0.46 & -0.02 \\
\hline & $\mathbf{P b}$ & SA & Gsb & Gse & $\mathrm{Gmb}$ & Gmm & VA & VMA & VFB & \\
\hline CPX80 & -0.26 & 0.37 & -0.44 & -0.56 & 0.72 & -0.43 & -0.76 & -0.73 & 0.69 & \\
\hline p0063 & 0.51 & 0.87 & 0.00 & -0.18 & 0.33 & -0.54 & -0.47 & -0.19 & 0.63 & \\
\hline p0125 & 0.34 & 0.97 & 0.11 & -0.30 & 0.47 & -0.55 & -0.60 & -0.36 & 0.72 & \\
\hline p025 & -0.01 & 0.97 & 0.34 & -0.46 & 0.58 & -0.45 & -0.65 & -0.55 & 0.72 & \\
\hline p05 & -0.22 & 0.87 & 0.42 & -0.54 & 0.59 & -0.40 & -0.64 & -0.63 & 0.68 & \\
\hline p1 & -0.33 & 0.80 & 0.44 & -0.58 & 0.60 & -0.36 & -0.64 & -0.67 & 0.65 & \\
\hline p2 & -0.41 & 0.75 & 0.46 & -0.58 & 0.61 & -0.30 & -0.63 & -0.69 & 0.61 & \\
\hline p56 & -0.43 & 0.67 & 0.52 & -0.41 & 0.52 & -0.09 & -0.47 & -0.56 & 0.45 & \\
\hline p8 & 0.42 & 0.02 & 0.79 & 0.54 & -0.51 & 0.30 & 0.54 & 0.62 & -0.46 & \\
\hline p112 & 0.73 & 0.39 & 0.40 & 0.40 & -0.29 & -0.09 & 0.21 & 0.46 & -0.02 & \\
\hline $\mathrm{Pb}$ & 1.00 & 0.15 & -0.10 & 0.47 & -0.39 & -0.24 & 0.24 & 0.60 & -0.05 & \\
\hline SA & 0.15 & 1.00 & 0.24 & -0.42 & 0.54 & -0.52 & -0.65 & -0.48 & 0.75 & \\
\hline Gsb & -0.10 & 0.24 & 1.00 & 0.14 & -0.15 & 0.28 & 0.23 & 0.15 & -0.24 & \\
\hline Gse & 0.47 & -0.42 & 0.14 & 1.00 & -0.49 & 0.74 & 0.68 & 0.77 & -0.65 & \\
\hline $\mathrm{Gmb}$ & -0.39 & 0.54 & -0.15 & -0.49 & 1.00 & -0.25 & -0.94 & -0.92 & 0.83 & \\
\hline $\mathrm{Gmm}$ & -0.24 & -0.52 & 0.28 & 0.74 & -0.25 & 1.00 & 0.57 & 0.40 & -0.69 & \\
\hline VA & 0.24 & -0.65 & 0.23 & 0.68 & -0.94 & 0.57 & 1.00 & 0.92 & -0.95 & \\
\hline VMA & 0.60 & -0.48 & 0.15 & 0.77 & -0.92 & 0.40 & 0.92 & 1.00 & -0.81 & \\
\hline VFB & -0.05 & 0.75 & -0.24 & -0.65 & 0.83 & -0.69 & -0.95 & -0.81 & 1.00 & \\
\hline
\end{tabular}

Where: correlation coefficients are marked in bold.

Table 7. $p$-values according to the significance of the correlation coefficients.

\begin{tabular}{ccccccccccc}
\hline & CPX80 & p0063 & p0125 & p025 & p05 & p1 & p2 & p56 & p8 & p112 \\
\hline CPX80 & - & 0.04 & 0 & 0 & 0.01 & 0 & 0 & 0.03 & 0 & 0 \\
p0063 & 0.04 & - & 0 & 0 & 0 & 0 & 0.01 & 0.03 & 0.62 & 0 \\
p0125 & 0 & 0 & - & 0 & 0 & 0 & 0 & 0 & 0.85 & 0 \\
p025 & 0 & 0 & 0 & - & 0 & 0 & 0 & 0 & 0.90 & 0.01 \\
p05 & 0.01 & 0 & 0 & 0 & - & 0 & 0 & 0 & 0.95 & 0.12 \\
p1 & 0 & 0 & 0 & 0 & 0 & - & 0 & 0 & 0.78 & 0.32 \\
p2 & 0 & 0.01 & 0 & 0 & 0 & 0 & - & 0 & 0.64 & 0.67 \\
p56 & 0.03 & 0.03 & 0 & 0 & 0 & 0 & 0 & - & 0.97 & 0.98 \\
p8 & 0 & 0.62 & 0.85 & 0.90 & 0.95 & 0.78 & 0.64 & 0.97 & - & 0 \\
p112 & 0 & 0 & 0 & 0.01 & 0.12 & 0.32 & 0.67 & 0.98 & 0 & - \\
Pb & 0.04 & 0 & 0.01 & 0.96 & 0.08 & 0.01 & 0 & 0 & 0 & 0 \\
SA & 0 & 0 & 0 & 0 & 0 & 0 & 0 & 0 & 0.87 & 0 \\
Gsb & 0 & 0.97 & 0.39 & 0.01 & 0 & 0 & 0 & 0 & 0 & 0 \\
Gse & 0 & 0.16 & 0.01 & 0 & 0 & 0 & 0 & 0 & 0 & 0 \\
Gmb & 0 & 0.01 & 0 & 0 & 0 & 0 & 0 & 0 & 0 & 0.02 \\
Gmm & 0 & 0 & 0 & 0 & 0 & 0 & 0.02 & 0.47 & 0.01 & 0.46 \\
VA & 0 & 0 & 0 & 0 & 0 & 0 & 0 & 0 & 0 & 0.10 \\
VMA & 0 & 0.14 & 0 & 0 & 0 & 0 & 0 & 0 & 0 & 0 \\
VFB & 0 & 0 & 0 & 0 & 0 & 0 & 0 & 0 & 0 & 0.88 \\
\hline
\end{tabular}


Table 7. Cont.

\begin{tabular}{cccccccccc}
\hline & Pb & SA & Gsb & Gse & Gmb & Gmm & VA & VMA & VFB \\
\hline CPX80 & 0.04 & 0 & 0 & 0 & 0 & 0 & 0 & 0 & 0 \\
p0063 & 0 & 0 & 0.97 & 0.16 & 0.01 & 0 & 0 & 0.14 & 0 \\
p0125 & 0.01 & 0 & 0.39 & 0.01 & 0 & 0 & 0 & 0 & 0 \\
p025 & 0.96 & 0 & 0.01 & 0 & 0 & 0 & 0 & 0 & 0 \\
p05 & 0.08 & 0 & 0 & 0 & 0 & 0 & 0 & 0 & 0 \\
p1 & 0.01 & 0 & 0 & 0 & 0 & 0 & 0 & 0 & 0 \\
p2 & 0 & 0 & 0 & 0 & 0 & 0.02 & 0 & 0 & 0 \\
p56 & 0 & 0 & 0 & 0 & 0 & 0.47 & 0 & 0 & 0 \\
p8 & 0 & 0.87 & 0 & 0 & 0 & 0.01 & 0 & 0 & 0 \\
p112 & 0 & 0 & 0 & 0 & 0.02 & 0.46 & 0.10 & 0 & 0.88 \\
Pb & - & 0.23 & 0.42 & 0 & 0 & 0.06 & 0.06 & 0 & 0.71 \\
SA & 0.23 & - & 0.05 & 0 & 0 & 0 & 0 & 0 & 0 \\
Gsb & 0.42 & 0.05 & - & 0.26 & 0.23 & 0.02 & 0.07 & 0.23 & 0.05 \\
Gse & 0 & 0 & 0.26 & - & 0 & 0 & 0 & 0 & 0 \\
Gmb & 0 & 0 & 0.23 & 0 & - & 0.05 & 0 & 0 & 0 \\
Gmm & 0.06 & 0 & 0.02 & 0 & 0.05 & - & 0 & 0 & 0 \\
VA & 0.06 & 0 & 0.07 & 0 & 0 & 0 & - & 0 & 0 \\
VMA & 0 & 0 & 0.23 & 0 & 0 & 0 & 0 & - & 0 \\
VFB & 0.71 & 0 & 0.05 & 0 & 0 & 0 & 0 & 0 & - \\
\hline
\end{tabular}

\subsection{Pavement Acoustic Properties Prediction Model}

Based on the correlation matrix, from the 19 criteria, the following criteria were selected to develop the CPX: SA, Pb, VA, VMA, and VFB. The criterion SA was selected since it comprises all the studied criteria of gradation. The air-void content, VA, was calculated using the values of Gmb and Gmm. The bitumen content, $\mathrm{Pb}$, was included in the regression model in order to observe its effect on asphalt pavement noise. Since all five criteria cannot be included in one model due to their intercorrelation, two linear regression models were developed:

$$
\mathrm{CPX}_{1}=f(\mathrm{VA}, \mathrm{SA} \cdot \mathrm{Pb}) \text { and } \mathrm{CPX} 2=f(\mathrm{VFB}, \mathrm{Pb}) \text {. }
$$

To develop the model and to test the assumptions, the $R$ software was used [2]. With the help of calculations, the model $\mathrm{CPX}_{1}$ was obtained:

$$
\mathrm{CPX}_{1}=99.109-0.203 \mathrm{VA}-0.016 \mathrm{SA} \cdot \mathrm{Pb} \text {. }
$$

The obtained model, $\mathrm{CPX}$, demonstrated that the value of $\mathrm{CPX}$ was more highly affected by the VA (with a standardized value of -0.845) compared to the SA.Pb (with a standardized value of -0.161 ).

In the second case, $\mathrm{CPX}_{2}=f(\mathrm{VFB}, \mathrm{Pb})$ the following model was obtained:

$$
\mathrm{CPX}_{2}=95.636+0.048 \mathrm{VFB}-0.278 \mathrm{~Pb}
$$

The obtained model, $\mathrm{CPX}$, showed that the value of $\mathrm{CPX}$ experienced a greater effect from the VFB (with a standardized value of 0.675 ) compared to the $\mathrm{Pb}$ (with a standardized value of -0.225 ).

The values of assumptions describing the reliability of the models $\mathrm{CPX}_{1}$ and $\mathrm{CPX}_{2}$ are given in Table 8 . The models that were obtained according to the coefficient of determination, $R^{2}$, adequately described the testing data; in both cases, $R^{2} \geq 0.20$. The ANOVA test showed that the model variables were statistically significant, in both cases the $p$-value was $<0.05$. Based on the Breusch-Pagan test results, it can be stated that the model $\mathrm{CPX}_{1}$ data were compatible with the homoscedasticity assumption since the $p$-value was $\geq 0.05$. In the case of the model, $\mathrm{CPX}_{2}$, an insignificant heteroskedasticity of the data was observed. Based on the VIF values, neither of the models possess multicollinearity. Measured versus predicted noise of $C P X$ at $80 \mathrm{~km} / \mathrm{h}$ for developed models $C P X_{1}$ and $C P X_{2}$ are given in Figure 5 . 
Table 8. Parameters of linear regression assumptions.

\begin{tabular}{ccc}
\hline Parameter & CPX $_{\mathbf{1}}$ Model Parameter Value & CPX $_{\mathbf{2}}$ Model Parameter Value \\
\hline R2 & 0.590 & 0.504 \\
ANOVA $p$-value & $2.24 \times 10^{-12}$ & $1.913 \times 10^{-10}$ \\
Shapiro-Wilk $p$-value & 0.00013 & 0.01811 \\
Breusch-Pagan $p$-value & 0.1541 & 0.045 \\
VIF & $\mathrm{VIF}(\mathrm{VA})=\mathrm{VIF}(\mathrm{SA} \cdot \mathrm{Pb})=1.338$ & $\mathrm{VIF}(\mathrm{VFB})=\mathrm{VIF}(\mathrm{Pb})=1.002$ \\
Bonferroni $p$-value & 0.00015 & 0.000522 \\
\hline
\end{tabular}
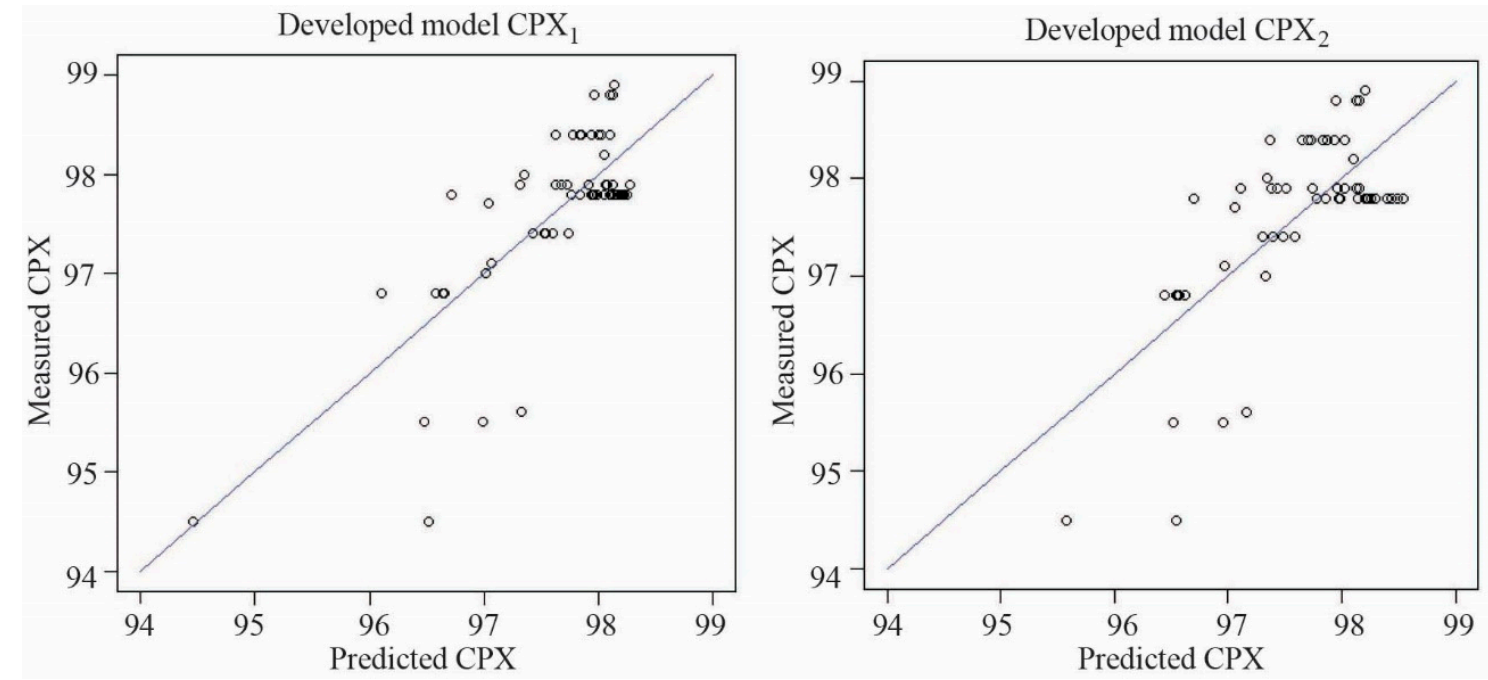

Figure 5. Measured versus predicted noise of $\mathrm{CPX}$ at $80 \mathrm{~km} / \mathrm{h}$ for developed models $\mathrm{CPX}_{1}$ and $\mathrm{CPX}_{2}$.

When testing the normality of the residuals according to the Shapiro-Wilk test and also when observing the PPplots (probability-probability plots) (Figure 6), the assumption on the normality of the residuals was not satisfied. In the case of the model, $\mathrm{CPX}_{1}$, after implementing the Shapiro-Wilk test the obtained $p$-value was $0.00013(<0.05)$ —the assumption on the normality of the residuals was not satisfied. In the case of the model, $\mathrm{CPX}$, after implementing the Shapiro-Wilk test, the obtained $p$-value was $0.018(<0.05)$ - the assumption on the normality of the residuals was not satisfied, although the residuals of the model $\mathrm{CPX}_{2}$ were almost normal.
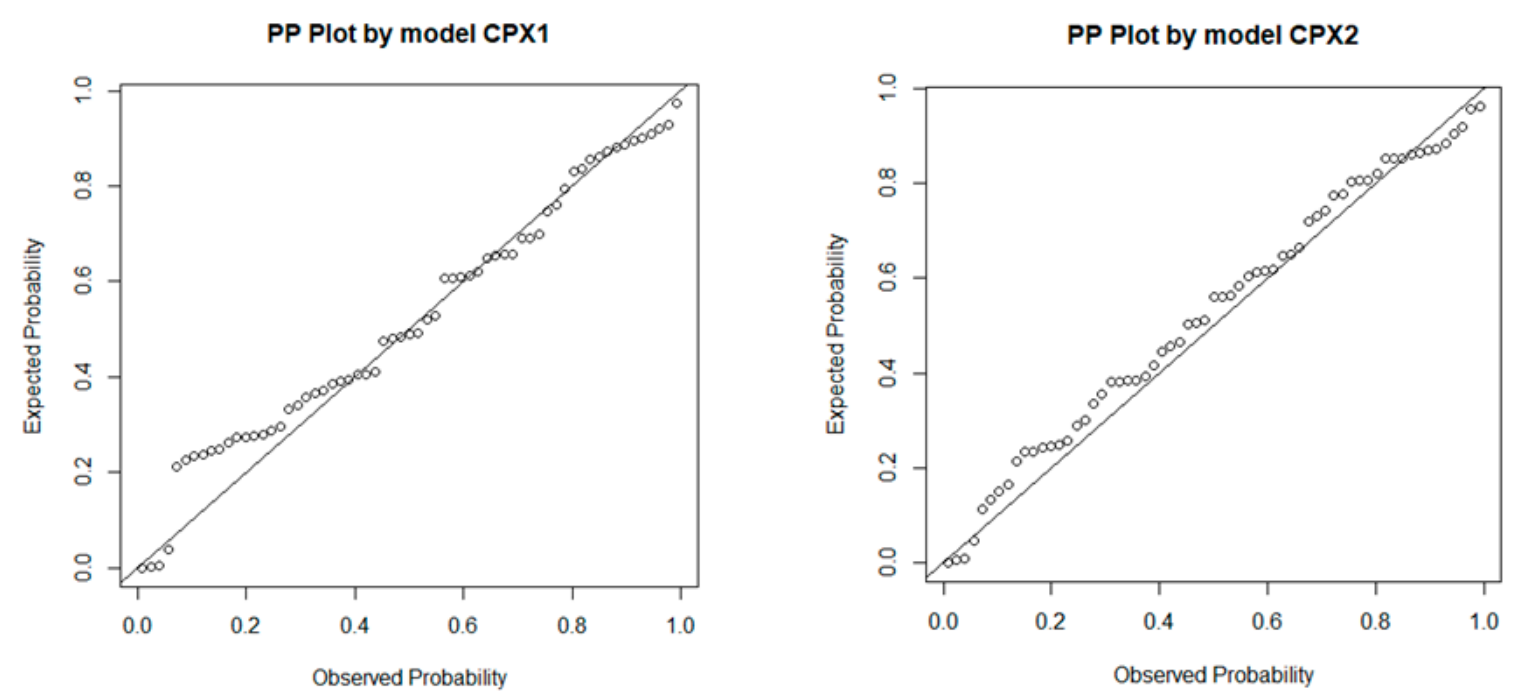

Figure 6. Probability-probability plot of developed models $\mathrm{CPX}_{1}$ and $\mathrm{CPX}_{2}$. 
The Bonferroni test showed that the models $\mathrm{CPX}$ and $\mathrm{CPX}$ contain outliers. When observing the Cook's distance plots, it is obvious that none of the Cook's distance values are larger than 1 , meaning that the studied data contain no outliers. The influence plot shows (Figure 7) that, in case of both models 8 (SMA $8 \mathrm{TM}$ ) and 19 (SMA $8 \mathrm{~S}$ ), observations of studentized residuals are lower than (-3), meaning that these observations have a relatively high effect on the results of the regression analysis. It was concluded that, generally, the data had no outliers.
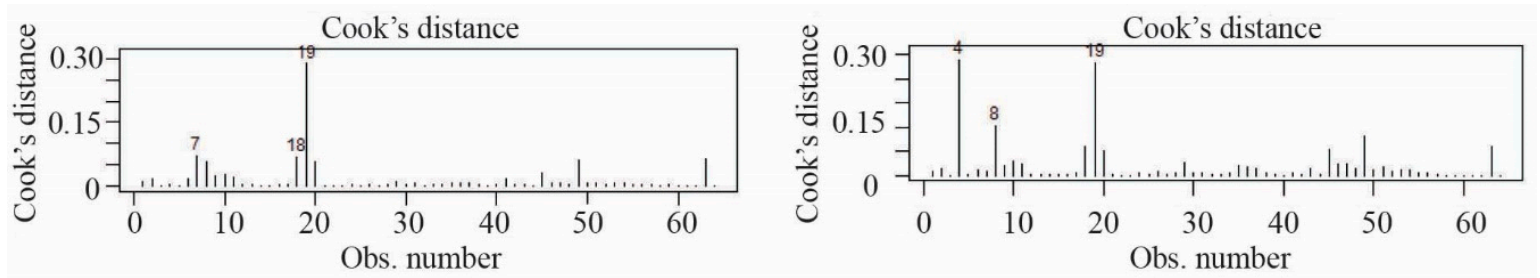

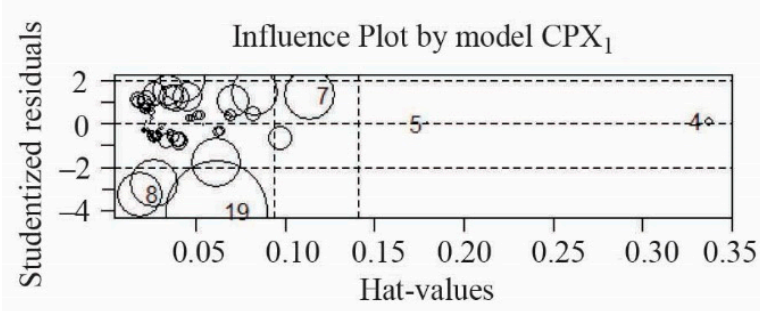

Circle size is proportial to Cooks' distance

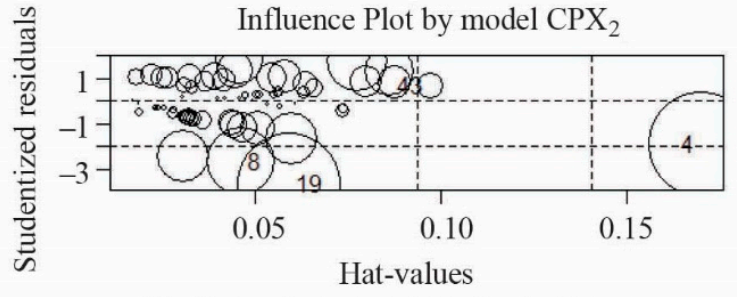

Circle size is proportial to Cooks' distance

Figure 7. Influence plot and Cook's distance of developed models $\mathrm{CPX}_{1}$ and $\mathrm{CPX}_{2}$.

\section{Conclusions}

This research involves analysis of the tire/road noise-level measurement values from 18 asphalt pavement sections and the volumetric properties of 64 test locations. Based on the findings of this research and the introduction of the linear model, the following conclusions are made:

1. The composition of the asphalt mixture in the investigated test sections significantly varies depending on the manufacturer:

- The bitumen content varies from $5.4 \%$ to $5.84 \%$ for AC $11 \mathrm{VN}$, from $4.38 \%$ to $4.88 \%$ for SA 16 , from $5.87 \%$ to $6.65 \%$ for SMA 11 S, from $5.91 \%$ to $6.9 \%$ for SMA 8 TM and from $6.80 \%$ to $7.20 \%$ for SMA $8 \mathrm{~S}$ asphalt mixtures;

- The air-void content varies from $1.0 \%$ to $3.7 \%$ for AC $11 \mathrm{VN}$, from $2.7 \%$ to $7.7 \%$ for SA 16 , from $1.6 \%$ to $3.9 \%$ for SMA $11 \mathrm{~S}$, from $6.3 \%$ to $11.6 \%$ for SMA 8 TM and from $3.5 \%$ to $5.3 \%$ for SMA $8 \mathrm{~S}$ asphalt mixtures;

- Voids in mineral aggregate (VMA) values vary from $12.5 \%$ to $13.7 \%$ for $\mathrm{AC} 11 \mathrm{VN}$, from $10.1 \%$ to $11.3 \%$ for SA 16 , from $13.8 \%$ to $15.4 \%$ for SMA 11 S, from $13.1 \%$ to $15.9 \%$ for SMA 8 TM and from $15.1 \%$ to $16.5 \%$ for SMA $8 \mathrm{~S}$ asphalt mixtures;

- Voids filled with bitumen (VFB) values vary from $78.3 \%$ to $92.8 \%$ for AC $11 \mathrm{VN}$, from $58.3 \%$ to $78.8 \%$ for SA 16 , from $78.5 \%$ to $90.5 \%$ for SMA 11 S, from $54.0 \%$ to $71.7 \%$ for SMA 8 TM and from $74.2 \%$ to $82.3 \%$ for SMA $8 \mathrm{~S}$ asphalt mixtures.

2. The tire/road noise measurements were performed at $80 \mathrm{~km} / \mathrm{h}$ using the CPX method for pavement sections at the first year of exploitation. The average noise level generated from tire/pavement interactions was $97.2 \mathrm{~dB}(\mathrm{~A})$ with a standard deviation of 1.38; therefore, all analyzed pavements comply definition of low-noise pavements.

3. According to the correlation analysis of the noise level and components of the low-noise asphalt mixture, it can be stated that CPX80 is highly correlated in terms of the percentage of aggregates passing through a $8.0 \mathrm{~mm}$ and $11.2 \mathrm{~mm}$ sieve size, the density of the mineral aggregate, the apparent 
density of the asphalt mixture, air-void content, voids in the mineral aggregate and voids in the mineral aggregate filled with bitumen.

4. During the analysis of the collected database on low-noise asphalt pavements, two pavement acoustic models were obtained, $\mathrm{CPX}$ and $\mathrm{CPX}_{2}$, for which the coefficients of determinations were 0.59 and 0.50 , respectively. However, the normality assumption of the Shapiro-Wilk test was not satisfied, mainly due to the limited database.

5. The analysis showed that there is a reasonable link between the composition of the asphalt wearing layer and the tire/road noise level. However, in order to provide a more complex prediction model, a database of low-volume asphalt mixtures should include no less than three different asphalt compositions, pavement textures and G-factor values for each type of asphalt mixture.

Author Contributions: R.K. and A.V. carried out the conceptualization and methodology of the research. R.K., O.Š., and R.S. perform data analysis. The article was written by R.K. and R.S. and edited as well as reviewed by A.V. and O.Š.

Funding: This project has received funding from the Research Council of Lithuania (LMTLT), agreement No S-MIP-17-137.

Conflicts of Interest: The authors declare no conflict of interest.

\section{Abbreviation}

$\begin{array}{ll}\text { AADT } & \text { annual average daily traffic } \\ \text { AC } & \text { dense asphalt concrete } \\ \text { ANOVA } & \text { basic analysis of variance } \\ \text { CPX } & \text { close-proximity method } \\ \text { DAMP } & \text { damping acoustical measurement parameter } \\ \text { ERNL } & \text { estimated road noisiness level } \\ \text { HMA } & \text { hot mix asphalt } \\ \text { Gmb } & \text { bulk specific gravity of compacted mixture } \\ \text { Gmm } & \text { maximum theoretical specific gravity } \\ \text { MPD } & \text { mean profile depth } \\ \text { NMS } & \text { nominal maximum size of asphalt mixture aggregates } \\ \text { OBSI } & \text { on-board sound intensity method } \\ \text { p0.063, p0.125 ... p11.2 } & \text { aggregate gradation sieve no and mesh size, mm } \\ \text { PA } & \text { porous asphalt } \\ \text { PP } & \text { probability-probability plot } \\ \text { Pb } & \text { bitumen content } \\ \text { SA } & \text { specific surface area of the aggregate } \\ \text { SI } & \text { shape index } \\ \text { SIL or IL } & \text { sound intensity level or intensity level } \\ \text { SMA } & \text { stone mastic asphalt mixture } \\ \text { TNM } & \text { traffic noise model } \\ \text { TMOA } & \text { low noise asphalt mixture } \\ \text { VA } & \text { air-void content } \\ \text { VIF } & \text { variance inflation factor } \\ \text { VFB } & \text { voids filed with bitumen } \\ \text { VMA } & \text { voids in mineral aggregate } \\ & \end{array}$

\section{References}

1. Regional Office Europe (WHO). Night Noise Guidelines for Europe; WHO Regional Office Europe: København, Denmark, 2014.

2. EC. Report from the Commission to the European Parliament and the Council: On the Implementation of the Environmental Noise Directive in Accordance with Article 11 of Directive 2002/49/EC; COM (2011) 321 final; EC: Brussel, Belgium, 2011. 
3. Vaitkus, A.; Vorobjovas, V.; Jagniatinskis, A.; Andriejauskas, T.; Fiks, B. Peculiarity of low noise pavement design under Lithuanian conditions. Balt. J. Road Bridg. Eng. 2014, 9, 155-163. [CrossRef]

4. Zofka, E.; Zofka, A.; Mechowski, T. Pavement noise measurements in Poland. In IOP Conference Series Materials Science and Engineering; IOP Publishing: Bristol, UK, 2017; Volume 236.

5. Bernhard, R.; Wayson, R. An introduction to tire/pavement noise of asphalt pavement. Inst. Safe Quiet 2005, $26,27$.

6. Donavan, P.R.; Rymer, B. Assessment of highway pavements for tire/road noise generation. SAE Trans. 2003, 112, 1829-1838.

7. Vaitkus, A.; Andriejauskas, T.; Vorobjovas, V.; Jagniatinskis, A.; Fiks, B.; Zofka, E. Asphalt wearing course optimization for road traffic noise reduction. Constr. Build. Mater. 2017, 152, 345-356. [CrossRef]

8. Sandberg, U.; Ejsmont, J. Tire/Road Noise Reference Book; INFORMEX: Kisa, Sweden, 2002.

9. Biligiri, K.P.; Kalman, B.; Samuelsson, A. Understanding the fundamental material properties of low-noise poroelastic road surfaces. Int. J. Pavement Eng. 2013, 14, 12-23. [CrossRef]

10. Biligiri, K.P.; Kaloush, K.; Uzan, J. Evaluation of asphalt mixtures' viscoelastic properties using phase angle relationships. Int. J. Pavement Eng. 2010, 11, 143-152. [CrossRef]

11. Bezemer-Krijnen, M.; Wijnant, Y.; De Boer, A. Tire-road noise measurements: Influence of tire tread and road characteristics. In Proceedings of the INTER-NOISE 2016-45th International Congress and Exposition on Noise Control Engineering: Towards a Quieter Future, Hamburg, Germany, 21 August 2016; pp. 2242-2253.

12. Cackler, E.T.; Ferragut, T.; Harrington, D.S. Evaluation of U.S. and European Concrete Pavement Noise Reduction Methods; National Transportation Library: Washington, DC, USA, 2006.

13. Aksnes, J. Environmentally Friendly Pavements; Norwegian Public Roads Administration: Oslo, Norway, 2009.

14. Son, S.; Al-Qadi, I.L.; Zehr, T. $4.75 \mathrm{~mm}$ SMA performance and cost-effectiveness for asphalt thin overlays. Int. J. Pavement Eng. 2016, 17, 799-809. [CrossRef]

15. Vaitkus, A.; Andriejauskas, T.; Vorobjovas, V.; Šernas, O.; Skrodenis, D. Acoustical aging of low noise pavements expressed by different measuring techniques. In Proceedings of the 5 th International Conference on Road and Rail Infrastructure, Zagreb, Croatia, 17-19 May 2018.

16. Vaitkus, A.; Andriejauskas, T.; Gražulyte, J.; Šernas, O.; Vorobjovas, V.; Kleiziene, R. Qualitative Criteria and Thresholds for Low Noise Asphalt Mixture Design; IOP Publishing: Bristol, UK, 2018; Volume 356.

17. Miljković, M.; Radenberg, M. Thin noise-reducing asphalt pavements for urban areas in Germany. Int. J. Pavement Eng. 2012, 13, 569-578. [CrossRef]

18. Losa, M.; Leandri, P.; Licitra, G. Mixture design optimization of low-noise pavements. Transp. Res. Rec. J. Transp. Res. Board 2013, 2372, 25-33. [CrossRef]

19. Kragh, J.; Bendtsen, H.; Hildebrand, G. Noise classification for tendering quiet asphalt wearing courses. Procedia Soc. Behav. Sci. 2012, 48, 570-579. [CrossRef]

20. Bendtsen, H.; Oddershede, J.; Quing Lu, A.R. Asphalt Pavement Texture and Noise; The National Academies of Sciences, Engineering, and Medicine: Washington, DC, USA, 2013; ISBN 9788770607506.

21. Ongel, A.; Kohler, E.; Lu, Q.; Harvey, J. Comparison of surface characteristics and pavement/tire noise of various thin asphalt overlays. Road Mater. Pavement Des. 2008, 9, 333-344. [CrossRef]

22. Chen, D.; Ling, C.; Wang, T.; Su, Q.; Ye, A. Prediction of tire-pavement noise of porous asphalt mixture based on mixture surface texture level and distributions. Constr. Build. Mater. 2018, 173, 801-810. [CrossRef]

23. Remisova, E.; Decky, M.; Kovac, M. The influence of the asphalt mixture composition on the pavement surface texture and noise emissions production. In Proceedings of the 14th International Multidisciplinary Scientific GeoConference SGEM 2014, Albena, Bulgaria, 17-26 June 2014.

24. Descornet, G. Low-noise road surfaces: European state of the art guy descornet 1. J. Assoc. Asph. Paving Technol. 2005, 74, 1059-1083.

25. Losa, M.; Leandri, P.; Bacci, R. Empirical rolling noise prediction models based on pavement surface characteristics empirical rolling noise prediction models based on pavement surface characteristics. Road Mater. Pavement Des. 2010, 11, 487-506. [CrossRef]

26. Gardziejczyk, W.; Gierasimiuk, P. Influence of texturing method on tire/road noise of cement concrete pavement. Int. J. Pavement Eng. 2018, 19, 1061-1076. [CrossRef]

27. Wu, C.M.; Lee, C.C.; Du, J.C.; Shen, D.H. Development of acoustical prediction model for asphalt pavements using grey system approach. Road Mater. Pavement Des. 2010, 11, 783-805. [CrossRef] 
28. Praticò, F.G. Roads and loudness: A more comprehensive approach. Road Mater. Pavement Des. 2001, 2, 359-377. [CrossRef]

29. EN 12697-27. Bituminous Mixtures-Test Methods_Part 27: Sampling; British Standards Institution (BSI): London, UK, 2017.

30. EN 12697-8. Bituminous Mixtures_Test Methods for Hot Mix Asphalt_Part 8: Determination of Void Characteristics of Bituminous Specimens; British Standards Institution (BSI): London, UK, 2003.

31. Li, X.; Williams, R.C.; Marasteanu, M.O.; Clyne, T.R.; Johnson, E. Investigation of in-place asphalt film thickness and performance of hot-mix asphalt mixtures. J. Mater. Civ. Eng. 2009, 21, 262-270. [CrossRef]

32. ISO/CD 11819-2. Acoustics-Measurement of the Influence of Road Surfaces on Traffic Noise_Part 2: The Close-Proximity Method; ISO: Geneva, Switzerland, 2000.

33. Achim Zeileis, T.H. Diagnostic checking in regression relationships. R News 2010, 2, 7-10.

34. Kleiber, C.; Zeileis, A. Applied Econometrics with R; Springer: New York, NY, USA, 2008; ISBN 978-0-387-77316-2.

35. DemŠar, J. Statistical comparisons of classifiers over multiple data sets. J. Mach. Learn. Res. 2006, 7, 1-30.

36. Ginevicius, R.; Podvezko, V. Objective and subjective approaches determining the criterion weights in multicriteria models. Transp. Telecommun. 2005, 6, 133-137.

(C) 2019 by the authors. Licensee MDPI, Basel, Switzerland. This article is an open access article distributed under the terms and conditions of the Creative Commons Attribution (CC BY) license (http://creativecommons.org/licenses/by/4.0/). 